\title{
A phase III randomized study to evaluate the efficacy and safety of CT-P13 compared with reference infliximab in patients with active rheumatoid arthritis: 54-week results from the PLANETRA study
}

Dae Hyun Yoo ${ }^{1}$, Artur Racewicz ${ }^{2}$, Jan Brzezicki ${ }^{3}$, Roman Yatsyshyn ${ }^{4}$, Edgardo Tobias Arteaga ${ }^{5}$, Asta Baranauskaite ${ }^{6}$, Carlos Abud-Mendoza', Sandra Navarra ${ }^{8}$, Vladimir Kadinov ${ }^{9}$, Irmgadt Goecke Sariego ${ }^{10}$, Seung Suh Hong ${ }^{11}$, Sung Young Lee ${ }^{11}$ and Won Park ${ }^{12^{*}}$

\begin{abstract}
Background: CT-P13 (Remsima ${ }^{\oplus}$, Inflectra ${ }^{\oplus}$ ) is a biosimilar of the infliximab reference product (RP; Remicade ${ }^{\oplus}$ ). The aim of this study was to compare the 54-week efficacy, immunogenicity, safety, pharmacokinetics (PK) and pharmacodynamics (PD) of CT-P13 and RP in patients with active rheumatoid arthritis (RA).

Methods: In this multinational phase III double-blind study, patients with active RA and an inadequate response to methotrexate (MTX) were randomized (1:1) to receive CT-P13 (3 mg/kg) or RP (3 mg/ $/ \mathrm{kg})$ at weeks 0, 2, 6 and then every 8 weeks to week 54 in combination with MTX (12.5-25 mg/week). Efficacy endpoints included American College of Rheumatology (ACR)20, ACR50 and ACR70 response rates, Disease Activity Score in 28 joints (DAS28), Simplified Disease Activity Index (SDAl), Clinical Disease Activity Index (CDAl), European League Against Rheumatism (EULAR) response rates, patient-reported outcomes and joint damage progression. Immunogenicity, safety and PK/ PD outcomes were also assessed.
\end{abstract}

Results: Of 606 randomized patients, 455 (CT-P13 233, RP 222) were treated up to week 54. At week 54, ACR20 response rate was highly similar between groups (CT-P13 74.7\%, RP $71.3 \%$ ). ACR50 and ACR70 response rates were also comparable between groups (CT-P13 $43.6 \%$ and $21.3 \%$, respectively; RP $43.1 \%$ and $19.9 \%$, respectively). DAS28, SDAI and CDAI decreased from baseline to week 54 to a similar extent with CT-P13 and RP. Radiographic progression measured by Sharp scores as modified by van der Heijde was also comparable. With both treatments, patient assessments of pain, disease activity and physical ability, as well as mean scores on the Medical Outcomes Study Short Form Health Survey (SF-36), improved markedly at week 14 and remained stable thereafter up to week 54. The proportion of patients positive for antidrug antibodies at week 54 was similar between the two groups: 41.1 $\%$ and $36.0 \%$ with CT-P13 and RP, respectively. CT-P13 was well tolerated and had a similar safety profile to RP. PK PD results were also comparable between CT-P13 and RP.

Conclusions: CT-P13 and RP were comparable in terms of efficacy (including radiographic progression), immunogenicity and PK/PD up to week 54. The safety profile of CT-P13 was also similar to that of RP. (Continued on next page)

\footnotetext{
* Correspondence: parkwon@inha.ac.kr

${ }^{12}$ Inha University Hospital, Incheon, Republic of Korea

Full list of author information is available at the end of the article
} 
(Continued from previous page)

Trial registration: ClinicalTrials.gov identifier: NCT01217086. Registered 4 Oct 2010.

Keywords: Biosimilar, CT-P13, Infliximab, Rheumatoid arthritis, Efficacy, Immunogenicity, Safety, Pharmacokinetics, ACR20, Sharp score

\section{Background}

Infliximab is a chimeric, anti-tumor necrosis factor (TNF) monoclonal antibody proven to be effective in patients with active rheumatoid arthritis (RA) not responding to methotrexate (MTX) [1, 2]. Over the past 15 years, the introduction of infliximab and other biologics has led to dramatic improvements in the management of RA, particularly in terms of enabling patients to achieve better outcomes [3]. However, there is an imbalance in the availability and affordability of these biologics worldwide due to their high costs $[4,5]$.

Some biologics, including infliximab, are at the end of their patent period. This fact, together with the high costs of these drugs, has prompted the recent development of biosimilar drugs. Biosimilars are highly similar to already approved innovator or "reference" biologics in terms of structure, efficacy, safety and quality [6, 7]. By virtue of their lower price, biosimilars have the potential to reduce healthcare costs relative to reference biologics [8-11], thereby increasing access to biologic drugs for patients who require them.

CT-P13 (Remsima ${ }^{\oplus}$, Inflectra ${ }^{\oplus}$ ) is a biosimilar of reference infliximab (Remicade ${ }^{\oplus}$ ), hereafter referred to as the reference product (RP). It has been approved by the European Medicines Agency for use in all the indications for which RP is licensed, including RA. CT-P13 and RP are the same in terms of their pharmaceutical form, strength, composition and route of administration [12]. Consequently, dosage and administration instructions for CT-P13 are the same as those for RP. Nonclinical evaluations have shown that CT-P13 and RP are comparable with regard to the potency of TNF neutralization, the key mechanism of action of infliximab, in WEHI 164 cells [12]. A number of other in vitro assays have also demonstrated the similarity of CT-P13 and RP in terms of levels of apoptosis and complementdependent cytotoxicity in a transmembrane TNFexpressing Jurkat cell line, and of antibody-dependent cellular cytotoxicity using peripheral blood mononuclear cells or whole blood from patients with Crohn's disease $[12,13]$.

The PLANETRA (Programme evaLuating the Autoimmune disease iNvEstigational drug cT-p13 in $R A$ patients) study was performed to assess the equivalence in efficacy of CT-P13 and RP treatment in patients with active RA. The primary 30 -week findings proved equivalency in efficacy outcomes between CT-P13 and RP in terms of American College of Rheumatology (ACR) response (intent-to-treat population) [14]. Safety, pharmacokinetics (PK) and pharmacodynamics (PD) profiles were also comparable between the two drugs. As reported here, the PLANETRA study researchers also evaluated the extended effects of CT-P13 compared with RP in patients with active RA up to 54 weeks, including efficacy, radiographic progression, immunogenicity, safety, PK and PD.

\section{Methods}

Full details of the methods of this study have been reported previously [14].

\section{Patients}

Patients aged 18-75 years were included if they had been diagnosed with RA according to the revised 1987 ACR classification criteria for $\geq 1$ year before screening. Active disease was defined as having at least six swollen joints, at least six tender joints and at least two of the following: morning stiffness for at least 45 minutes, erythrocyte sedimentation rate $(\mathrm{ESR})>28 \mathrm{~mm} / \mathrm{h}$ or serum C-reactive protein (CRP) concentration $>2.0 \mathrm{mg} /$ dl. Eligible patients had not responded adequately to MTX for $\geq 3$ months and were required to have received a stable MTX dose (12.5-25 mg/week) for $\geq 4$ weeks before screening.

\section{Study design and treatment}

This randomized, double-blind, multicenter, multinational, parallel-group, prospective phase III study (ClinicalTrials.gov identifier NCT01217086) was performed at 100 study centers across 19 countries in Europe, Asia, Latin America and the Middle East. Patients were randomly assigned (1:1 ratio) to receive 3 $\mathrm{mg} / \mathrm{kg}$ of CT-P13 (CELLTRION Inc, Incheon, Republic of Korea) or RP (Janssen Biotech Inc, Horsham, PA, USA) via a 2 -h intravenous infusion. Patients were treated at weeks 0,2 and 6 and then received a further six infusions every 8 weeks until week 54 . Patients were premedicated with an antihistamine as needed. MTX and folic acid were coadministered to all patients. The study was conducted according to the Declaration of Helsinki and International Committee on Harmonisation Good Clinical Practice guidelines. The protocol was approved by regulatory authorities and the ethics 
committees of each study site. All patients provided written informed consent.

\section{Study endpoints and assessments}

Efficacy, PK, PD and safety parameters were evaluated up to week 54. The primary endpoint of this study was the ACR20 response rate at week 30. Equivalence of efficacy according to ACR20 criteria was concluded if the $95 \%$ confidence interval (CI) for the treatment difference was within $\pm 15 \%$. Efficacy parameters were evaluated at baseline and at weeks 14, 30 and 54. Eligible patients were followed for ACR20, ACR50, ACR70, Disease Activity Score in 28 joints (DAS28), Simplified Disease Activity Index (SDAI), Clinical Disease Activity Index (CDAI) and European League Against Rheumatism (EULAR) response rate. Patient-reported outcomes (PROs) were evaluated using patient assessment of pain on the visual analogue scale (VAS), VAS patient global assessment of disease activity, the Health Assessment Questionnaire (HAQ) estimate of physical ability and the Medical Outcomes Study Short Form Health Survey (SF-36). To assess joint damage progression (JDP), radiographs obtained at baseline and at week 54 were evaluated with the "paired review" method; this evaluation was performed by two independent readers without knowledge of the time point of the radiographs. Individual component scores for JDP were calculated according to the van der Heijde modification of the Sharp scoring system, and used the mean score of two readers [15]. With respect to immunogenicity, the proportion of patients positive for antidrug antibodies (ADAs) was evaluated at screening and at weeks 14, 30 and 54 [14]. The neutralizing activity of ADAs (NAbs) was also assessed by a flow-through immunoassay method using the Gyros immunoassay platform (Gyros AB, Uppsala, Sweden). For safety, adverse events (AEs) and changes in laboratory parameters were monitored throughout the study. A treatment-emergent $\mathrm{AE}$ (TEAE) was defined as any event not present before exposure to study treatment or an event that worsened in intensity or frequency after exposure to study treatment. At each planned visit, patients were screened for tuberculosis (TB) by clinical examination with careful history taking. For patients living in countries with an increased TB prevalence, interferon $\gamma$-release assay (IGRA; QuantiFERON-TB Gold-IT, QIAGEN, Hilden, Germany) was rechecked at weeks 14, 30 and 54 to identify positive conversion from negative results at baseline [14]. Latent TB was defined as a positive conversion of IGRA together with a negative examination on chest $\mathrm{x}$-ray. Patients were monitored for infusion-related reactions, including hypersensitivity and anaphylactic reaction.

PK evaluations included mean maximum serum drug concentration and mean minimum serum drug concentration. PD evaluations included CRP and ESR. Serum blood samples were obtained immediately before dosing, at the end of the infusion and $1 \mathrm{~h}$ after the infusion for PK assessments, and immediately before dosing for PD assessments.

Post hoc efficacy endpoints included the proportion of patients achieving ACR/EULAR remission by visit (Boolean-based, defined as swollen joint count $[\mathrm{SJC}]$ and tender joint count [TJC] less than or equal to one, CRP $\leq 1$ $\mathrm{mg} / \mathrm{dl}$, and patient global VAS $\leq 1$ using a $0-10$ scale; or index-based, defined as SDAI $\leq 3.3$ ) and the proportion of patients who had no radiographic progression in total Sharp score ( $\leq 0$ or $\leq 0.5$ units of change from baseline).

\section{Statistical analyses}

Statistical analyses were performed using SAS software version 9.1.3 or later (SAS Institute, Cary, NC, USA). Efficacy analyses were performed in the per-protocol (PP) population, which included all randomly assigned patients who did not have any major protocol deviations, using the as-observed method. The JDP analysis was performed in the intent-to-treat population (ITT), which included all randomly assigned patients. ACR response rates were also evaluated in the ITT population, as well as the PP population, using nonresponder imputation (NRI) for missing values. Exact binomial analyses and sensitivity analyses were performed for the ACR endpoints. Descriptive statistics were performed for DAS28, SDAI, CDAI, EULAR response, JDP, PROs including patient assessment of pain using the VAS, patient assessment of disease activity using the VAS, HAQ and SF-36. EULAR response criteria were analyzed using a proportional odds model stratified by region and CRP. Analysis of DAS28 was by analysis of covariance (ANCOVA) with treatment as a fixed effect and baseline DAS28, region and CRP category as covariates. Additional analyses were carried out for assessment of JDP, including patients with missing data (incomplete images) at week 54. Details of the methods have been reported previously [16].

Safety assessments were conducted in all patients who received at least one part infusion of study drug (safety population). The PK-PD population consisted of all patients who received either study drug during the 30week blinded study period and had at least one PK-PD concentration data value.

Sensitivity analyses included ACR responses using a last observation carried forward (LOCF) approach in the ITT population; descriptive statistics of DAS28, SDAI, CDAI and EULAR response; and PROs in the ITT population. For post hoc efficacy endpoints, NRI was used for the calculation of ACR/EULAR remission rates. Linear interpolation or extrapolation was used to calculate the proportion of patients who had no radiographic progression in total Sharp score. 


\section{Results}

\section{Patient disposition and baseline characteristics}

Of the 606 randomized patients, most $(n=455)$ were treated up to week 54: 233 (77.2 \%) of 302 with CT-P13 and $222(73.0 \%)$ of 304 with RP (Fig. 1). As has been reported previously [14], baseline patient demographics and disease characteristics were similar between the two groups (Table 1).

\section{Efficacy}

Overall, efficacy results for CT-P13 up to week 54 were generally comparable to those observed with RP. No statistical differences were observed for any efficacy endpoint. The primary endpoint of PLANETRA (ACR20 response at week 30) was equivalent between the two treatment groups [14]. The ACR20, ACR50 and ACR70 treatment responses were analogous between the two treatment groups throughout the course of the study (Fig. 2). At week 54 in the CT-P13 versus RP groups, the ACR20, ACR50 and ACR70 responses in the PP population were $74.7 \%$ (168 of 225) versus $71.3 \%$ (154 of 216), $43.6 \%$ (98 of 225) versus $43.1 \%$ (93 of 216 ) and $21.3 \%$ (48 of 225) versus $19.9 \%$ (43 of 216), respectively. ACR responses in the ITT population are shown in Additional file 1 and were also similar between the two treatment groups, regardless of the method of missing data imputation (NRI or LOCF).

Disease activity as measured by DAS28-ESR, DAS28CRP, SDAI and CDAI decreased from baseline through to week 54 in the PP population as well as in the ITT population (Fig. 3a-d and Additional file 2A-D). For all of these parameters, the reductions were comparable between the CT-P13 and RP treatment groups. In the CT-P13 group at week 54, the mean decreases from baseline in DAS28-ESR, DAS28-CRP, SDAI and CDAI scores were 2.4, 2.3, 26.3 and 25.7, respectively, in the $\mathrm{PP}$ population. The respective mean values for RP were $2.4,2.2,24.6$ and 24.0. There was no evidence of a difference between the two treatment groups in change from baseline in DAS28-ESR or DAS28-CRP at each time point at the $5 \%$ level of significance (DAS28-ESR treatment differences [95\% CIs] $-0.11[-0.31,0.10]$ at week $14,-0.10[-0.33,0.13]$ at week 30 and $-0.05[-0.30$, 0.19 ] at week 54; DAS28-CRP treatment differences $-0.15[-0.34,0.05]$ at week $14,-0.06[-0.27,0.16]$ at week 30 and $-0.07[-0.30,0.17]$ at week 54 in the PP population). Likewise, the proportion of patients with a good and moderate EULAR response to treatment was similar between the two treatment groups throughout the study in both the PP and the ITT populations (EULAR [ESR] and EULAR [CRP]) (Fig. 3e-f and Additional file 2E-F). With CT-P13 at week 54, $86.0 \%$ (191 of 222) and $87.4 \%$ (194 of 222) of patients had a moderate or good response according to EULAR (ESR) and EULAR (CRP) criteria, respectively, in the PP population. Respective values for RP were $81.2 \%$ (177 of 218 ) and $82.5 \%$ (179 of 217), respectively, in the PP population.

In terms of PROs (Table 2 and Additional file 3), mean decreases in VAS score for patient assessment of pain from baseline were similar between the two treatment groups in both the PP population and the ITT population. Mean baseline VAS scores for patient assessment of pain for CT-P13 and RP, respectively, were 65.7 and 65.5 in the PP population. Respective mean decreases

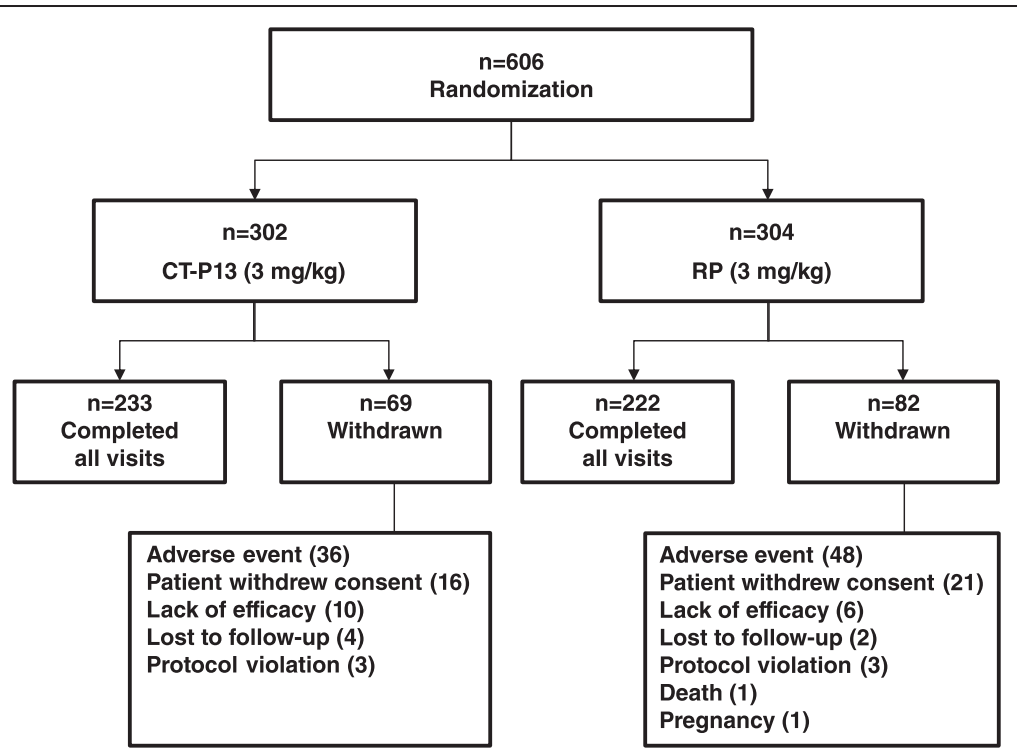

Fig. 1 Patient disposition. A total of 606 patients were randomized into either the CT-P13 group $(n=302)$ or the RP group $(n=304)$. A total of 151 patients were withdrawn for the stated reasons. The first patient was screened in November 2010 , and the last patient visit was in July 2012. RP reference product (i.e., reference infliximab) 
Table 1 Baseline patient demographics and disease characteristics

\begin{tabular}{|c|c|c|c|}
\hline & CT-P13 3 mg/kg $(n=302)$ & $\mathrm{RP} 3 \mathrm{mg} / \mathrm{kg}(n=304)$ & Total $(N=606)$ \\
\hline Age, median, years (range) & $50(18-75)$ & $50(21-74)$ & $50(18-75)$ \\
\hline \multicolumn{4}{|l|}{ Sex, $n(\%)$} \\
\hline Female & $245(81.1)$ & $256(84.2)$ & $501(82.7)$ \\
\hline Male & $57(18.9)$ & $48(15.8)$ & $105(17.3)$ \\
\hline \multicolumn{4}{|l|}{ Ethnicity, n (\%) } \\
\hline Asian & $34(11.3)$ & $37(12.2)$ & $71(11.7)$ \\
\hline Black & $2(0.7)$ & $1(0.3)$ & $3(0.5)$ \\
\hline White & $220(72.8)$ & $222(73.0)$ & $442(72.9)$ \\
\hline Other & $46(15.2)$ & $44(14.5)$ & $90(14.9)$ \\
\hline Height, cm, median (range) & $162.3(144.0-186.0)$ & $162.0(124.0-190.0)$ & $162.0(124.0-190.0)$ \\
\hline Weight, kg, median (range) & $69.0(36.5-134.0)$ & $68.0(36.0-136.0)$ & $68.6(36.0-136.0)$ \\
\hline BMI, kg/m², median (range) & $26.3(13.9-49.8)$ & $25.4(15.0-53.1)$ & $25.9(13.9-53.1)$ \\
\hline Anti-CCP antibody-positive, $n$ (\%) & $228(75.5)$ & $233(76.6)$ & $461(76.1)$ \\
\hline IgA RF-positive, $n$ (\%) & $131(43.4)$ & $134(44.1)$ & $265(43.7)$ \\
\hline IgM RF-positive, $n$ (\%) & $225(74.5)$ & $220(72.4)$ & $445(73.4)$ \\
\hline IgG RF-positive, $n$ (\%) & $173(57.3)$ & $171(56.3)$ & $344(56.8)$ \\
\hline \multicolumn{4}{|l|}{ Joint count } \\
\hline TJC, 68 joints & $25.6 \pm 13.9$ & $24.0 \pm 12.9$ & $24.8 \pm 13.4$ \\
\hline SJC, 66 joints & $16.2 \pm 8.7$ & $15.2 \pm 8.3$ & $15.7 \pm 8.5$ \\
\hline TJC, 28 joints & $15.9 \pm 6.4$ & $15.1 \pm 6.1$ & $15.5 \pm 6.2$ \\
\hline SJC, 28 joints & $12.0 \pm 4.9$ & $11.2 \pm 4.7$ & $11.6 \pm 4.8$ \\
\hline Duration of prior MTX therapy, weeks & $97.7 \pm 141.2$ & $89.4 \pm 96.5$ & $93.6 \pm 120.8$ \\
\hline MTX dose, mg & $15.6 \pm 3.1$ & $15.6 \pm 3.2$ & $15.6 \pm 3.1$ \\
\hline CDAl & $40.9 \pm 11.5$ & $39.3 \pm 11.1$ & $40.1 \pm 11.3$ \\
\hline SDAI & $42.8 \pm 11.9$ & $41.2 \pm 11.7$ & $42.0 \pm 11.8$ \\
\hline CRP, mg/dl & $1.9 \pm 2.5$ & $1.9 \pm 2.2$ & $1.9 \pm 2.4$ \\
\hline $\mathrm{ESR}, \mathrm{mm} / \mathrm{h}$ & $46.6 \pm 22.4$ & $48.5 \pm 22.6$ & $47.5 \pm 22.5$ \\
\hline DAS28-CRP & $5.9 \pm 0.8$ & $5.8 \pm 0.9$ & $5.8 \pm 0.9$ \\
\hline HAQ & $1.6 \pm 0.6$ & $1.6 \pm 0.6$ & $1.6 \pm 0.6$ \\
\hline Patient assessment of pain & $65.9 \pm 17.4$ & $65.5 \pm 17.2$ & $65.7 \pm 17.3$ \\
\hline Patient global assessment of disease activity & $65.7 \pm 17.2$ & $65.4 \pm 17.0$ & $65.5 \pm 17.1$ \\
\hline Physician global assessment of disease activity & $64.7 \pm 14.3$ & $65.0 \pm 13.5$ & $64.8 \pm 13.9$ \\
\hline
\end{tabular}

$B M I$ body mass index, CCP cyclic citrullinated peptide, CDAI Clinical Disease Activity Index, CRP C-reactive protein, DAS28 Disease Activity Score in 28 joints, ESR erythrocyte sedimentation rate, HAQ Health Assessment Questionnaire, $l g$ immunoglobulin, $M T X$ methotrexate, $R F$ rheumatoid factor, $R P$ reference product (i.e., reference infliximab), SD standard deviation, SDAI Simplified Disease Activity Index, SJC swollen joint count, TJC tender joint count

Except where indicated otherwise, values are mean \pm SD

from baseline were 29.6 versus 27.1 at week 14, 29.5 versus 27.7 at week 30 and 30.2 versus 28.4 at week 54 . For patient global assessment of disease activity, mean decreases from baseline were also similar in both groups. The respective mean baseline VAS scores for patient global assessment of disease activity for CT-P13 and RP were 65.1 versus 65.3 in the PP population. Respective mean decreases from baseline were 29.5 versus 25.5 at week 14, 28.1 versus 26.9 at week 30 and 30.3 versus 26.6 at week 54. Mean score for the HAQ estimate of physical ability decreased from baseline at weeks 14, 30 and 54 in each treatment arm. Mean decreases from baseline were again similar in both groups. The respective mean baseline HAQ estimate of physical ability for CT-P13 and RP was 1.61 versus 1.54 in the PP population. The respective mean decreases from baseline were 0.59 versus 0.50 at week $14,0.60$ versus 0.51 at week 30 and 0.60 versus 0.52 at week 54 .

Throughout the study, mean SF-36 score increased from baseline to week 54 in both groups. Scores were 


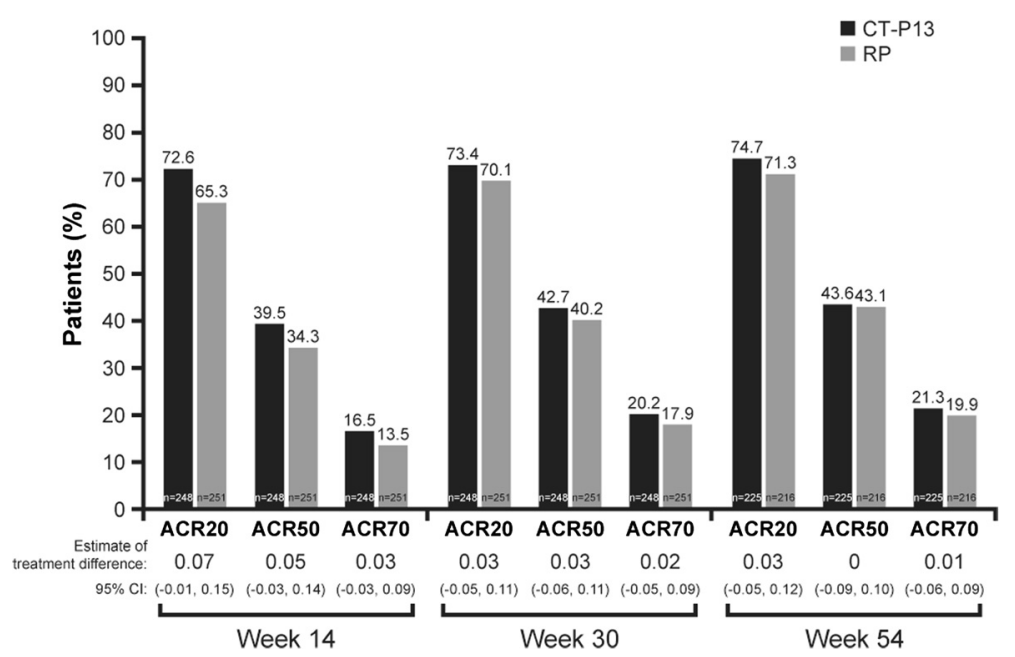

Fig. 2 American College of Rheumatology (ACR) response rates over time in the per-protocol population, with nonresponder imputation approach. To estimate the difference in proportions between the two treatment groups, we used the exact binomial test. ACR20, ACR50 and ACR70 denote the ACR $20 \%, 50 \%$ and $70 \%$ improvement criteria, respectively. Cl confidence interval, RP reference product (i.e., reference infliximab)

similar between CT-P13 and RP groups for all components of the SF-36. For the physical component summary, the mean increase from baseline to week 54 was 7.6 and 6.6 with CT-P13 and RP, respectively, in the PP population. For the mental component summary, the mean increase from baseline to week 54 was 7.1 and 6.9 with CT-P13 and RP, respectively, in the PP population. The proportion of patients achieving remission was similar between groups throughout the study in both Boolean-based and index-based (SDAI) ACR/EULAR remission criteria in the ITT population using the NRI approach (Fig. 4).

\section{Radiologic progression}

In total, 336 patients had radiographs at both baseline and week 54 and were eligible for assessment of JDP. Mean total Sharp scores at baseline were 68.3 in the CTP13 group and 64.8 in the RP group. The mean change from baseline to week 54 in JDP was similar between the CT-P13 and RP treatment groups with respect to total Sharp score $(1.0 \pm 6.3$ versus $0.6 \pm 5.6, p=0.5463)$, joint space narrowing score $(0.4 \pm 4.2$ versus $0.7 \pm 4.0, p=$ $0.4852)$ and erosion score $(0.7 \pm 3.9$ versus $0.0 \pm 3.4, p=$ 0.0795). Changes in total Sharp score from baseline to week 54 were $1.3 \pm 9.3$ and $0.7 \pm 7.0$ for CT-P13 and RP $(p=0.3171)$, respectively, when ANCOVA was used. There was no impact of the choice of imputation (ANCOVA, simple linear extrapolation, or no missing data imputation).

The proportion of patients who had no radiographic progression in total Sharp score was similar in both groups ( $\leq 0$ units of change from baseline: $51.7 \%$ [153 of 296] and 51.4 \% [151 of 294] in the CT-P13 and RP groups, respectively $[p=1.0000] ; \leq 0.5$ units of change from baseline: $58.1 \%$ [172 of 296] and $57.8 \%$ [170 of 294] [ $p=1.0000]$, respectively, with linear interpolation or extrapolation).

\section{Immunogenicity}

The proportion of patients positive for ADAs at week 54 was similar between the two treatment groups: 124 (41.1 $\%)$ and 108 (36.0 \%) in the CT-P13 and RP groups, respectively. In general, almost all patients with a positive ADA result were also positive for NAbs.

\section{Safety}

Among 606 patients randomized (302 and 304 patients in the CT-P13 and RP groups, respectively), 300 and 302 patients initiated study treatment. Owing to incorrect kits' being dispensed, two patients in the RP group received one dose of CT-P13. Therefore, the safety population comprised 302 patients in the CT-P13 group and 300 in the RP group.

In general, CT-P13 was well tolerated and had a safety profile similar to that of RP. Overall, TEAEs were reported for 213 patients $(70.5 \%)$ in the CT-P13 group and 211 patients $(70.3 \%)$ in the RP group. TEAEs considered to be related to treatment occurred in $132 \mathrm{pa}$ tients $(43.7 \%)$ in the CT-P13 group and 135 patients $(45.0 \%)$ in the RP group. The most frequently reported drug-related TEAEs (Table 3), occurring in at least nine patients in either treatment arm, were as follows in order of frequency: (1) for CT-P13, infusion-related reaction, upper respiratory tract infection, latent $\mathrm{TB}$, abnormal liver function test, lower respiratory tract infection and urinary tract infection; and (2) for RP, infusionrelated reaction, latent $\mathrm{TB}$, upper respiratory tract infection, abnormal liver function test, urinary tract infection 


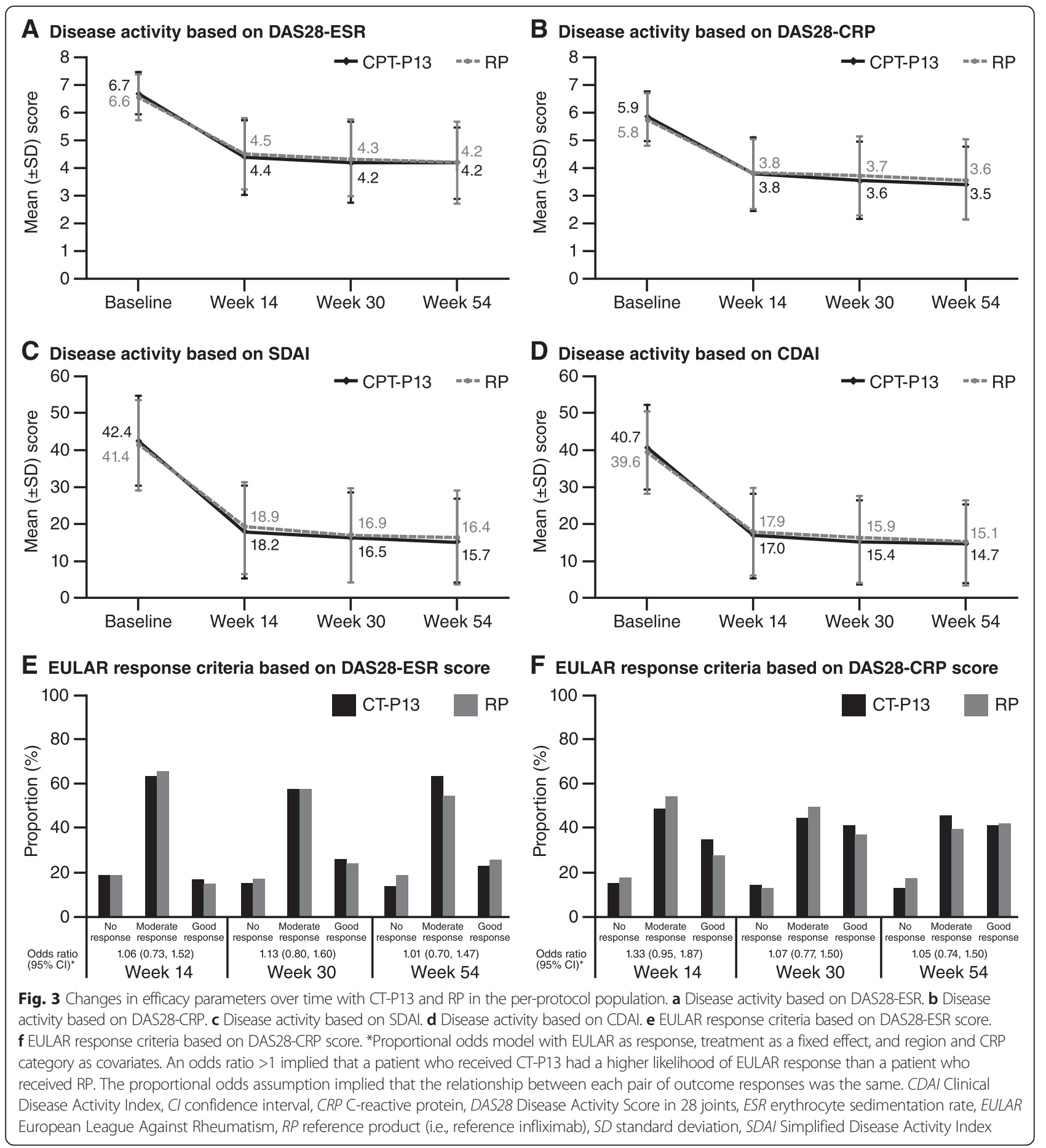

and lower respiratory tract infection. In the CT-P13 and $\mathrm{RP}$ treatment groups, infusion-related reactions were reported for 30 patients (9.9\%) and 43 patients (14.3\%), respectively.

Active TB was reported in three patients $(1 \%)$ in the CT-P13 group and no patients in the RP group. Of the three patients with active TB, one patient was diagnosed with TB based on clinical judgment alone rather than on a positive identification of Mycobacterium. The proportion of patients who had a negative IGRA result at screening followed by a positive IGRA result during study drug exposure was similar (39 [12.9\%] and 38 [12.7 \%] patients in the CT-P13 and RP groups, respectively). Among these, 28 (9.3 \%) and 26 (8.7 \%) patients, respectively, were reported as having a latent TB TEAE based on the judgment of investigators, and 24 (7.9 \%) 
Table 2 Improvement in patient-reported outcomes with CT-P13 and RP in the per-protocol population

\begin{tabular}{|c|c|c|c|c|c|c|}
\hline \multirow[b]{2}{*}{ Time point } & \multicolumn{3}{|c|}{ CT-P13 (3 mg/kg) } & \multicolumn{3}{|c|}{$\mathrm{RP}(3 \mathrm{mg} / \mathrm{kg})$} \\
\hline & $n$ & Actual result (mean $\pm \mathrm{SD})$ & Change from baseline (mean $\pm \mathrm{SD})$ & $n$ & Actual result (mean $\pm \mathrm{SD}$ ) & Change from baseline (mean $\pm S D$ ) \\
\hline \multicolumn{7}{|c|}{ VAS score for the patient assessment of pain } \\
\hline Baseline & 248 & $65.7 \pm 17.8$ & - & 251 & $65.5 \pm 17.7$ & - \\
\hline Week 14 & 248 & $36.1 \pm 21.4$ & $-29.6 \pm 23.3$ & 250 & $38.3 \pm 22.2$ & $-27.1 \pm 23.1$ \\
\hline Week 30 & 248 & $36.2 \pm 22.9$ & $-29.5 \pm 25.6$ & 250 & $37.7 \pm 23.6$ & $-27.7 \pm 24.9$ \\
\hline Week 54 & 226 & $35.0 \pm 21.2$ & $-30.2 \pm 23.8$ & 220 & $37.4 \pm 24.7$ & $-28.4 \pm 26.9$ \\
\hline \multicolumn{7}{|c|}{ VAS score for the patient global assessment of disease activity } \\
\hline Baseline & 248 & $65.1 \pm 17.5$ & - & 251 & $65.3 \pm 17.3$ & - \\
\hline Week 14 & 248 & $35.6 \pm 21.1$ & $-29.5 \pm 22.1$ & 249 & $39.7 \pm 22.5$ & $-25.5 \pm 24.4$ \\
\hline Week 30 & 247 & $37.0 \pm 22.3$ & $-28.1 \pm 25.9$ & 250 & $38.4 \pm 23.4$ & $-26.9 \pm 25.5$ \\
\hline Week 54 & 225 & $34.9 \pm 20.7$ & $-30.3 \pm 24.3$ & 220 & $38.7 \pm 25.3$ & $-26.6 \pm 27.8$ \\
\hline \multicolumn{7}{|c|}{ HAQ estimate of physical ability } \\
\hline Baseline & 248 & $1.61 \pm 0.56$ & - & 251 & $1.54 \pm 0.58$ & - \\
\hline Week 14 & 248 & $1.02 \pm 0.62$ & $-0.59 \pm 0.55$ & 251 & $1.04 \pm 0.64$ & $-0.50 \pm 0.50$ \\
\hline Week 30 & 248 & $1.01 \pm 0.64$ & $-0.60 \pm 0.60$ & 251 & $1.03 \pm 0.66$ & $-0.51 \pm 0.56$ \\
\hline Week 54 & 226 & $0.99 \pm 0.61$ & $-0.60 \pm 0.61$ & 220 & $1.02 \pm 0.64$ & $-0.52 \pm 0.59$ \\
\hline \multicolumn{7}{|c|}{ SF-36 score (physical component summary) } \\
\hline Baseline & 247 & $31.4 \pm 6.1$ & - & 251 & $31.8 \pm 7.2$ & - \\
\hline Week 14 & 247 & $38.9 \pm 7.6$ & $7.5 \pm 7.1$ & 251 & $37.6 \pm 7.9$ & $5.8 \pm 6.8$ \\
\hline Week 30 & 248 & $38.6 \pm 7.9$ & $7.1 \pm 7.9$ & 250 & $38.3 \pm 8.0$ & $6.5 \pm 7.6$ \\
\hline Week 54 & 226 & $39.2 \pm 7.5$ & $7.6 \pm 8.1$ & 220 & $38.6 \pm 8.7$ & $6.6 \pm 8.4$ \\
\hline \multicolumn{7}{|c|}{ SF-36 score (mental component summary) } \\
\hline Baseline & 247 & $36.8 \pm 10.4$ & - & 251 & $38.4 \pm 11.3$ & - \\
\hline Week 14 & 247 & $43.4 \pm 10.7$ & $6.6 \pm 10.2$ & 251 & $44.9 \pm 9.6$ & $6.5 \pm 10.4$ \\
\hline Week 30 & 248 & $44.0 \pm 10.2$ & $7.1 \pm 10.0$ & 251 & $45.0 \pm 10.3$ & $6.6 \pm 10.4$ \\
\hline Week 54 & 226 & $43.9 \pm 9.9$ & $7.1 \pm 10.1$ & 220 & $45.1 \pm 10.0$ & $6.9 \pm 11.2$ \\
\hline
\end{tabular}

HAQ Health Assessment Questionnaire, RP reference product (i.e., reference infliximab), SD standard deviation, SF-36 Medical Outcomes Study Short Form Health Survey, VAS visual analogue scale $(\mathrm{mm})$

and $20(6.7 \%)$ patients, respectively, started TB prophylaxis with isoniazid.

The majority of TEAEs were mild to moderate in severity and did not lead to discontinuation. Treatment-emergent serious AEs were reported in 42 patients (13.9\%) in the CT-P13 group, and 31 patients (10.3\%) in the RP group. Among them, 23 patients $(7.6 \%)$ in the CT-P13 group and 14 patients (4.7\%) in the RP group were considered to have events related to treatment (Additional file 4). The
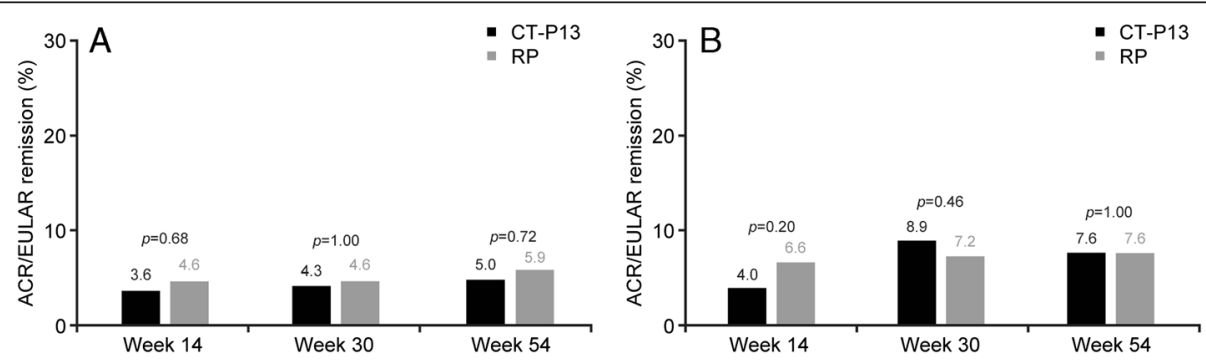

Fig. 4 Proportion of patients with ACR/EULAR remission in the intent-to-treat population, with nonresponder imputation approach. a ACR/EULAR remission by Boolean-based criterion. $\mathbf{b}$ ACR/EULAR remission by index-based criterion (SDAI). $p$ value was calculated using Fisher's exact test. ACR American College of Rheumatology, EULAR European League Against Rheumatism, RP reference product (i.e., reference infliximab), SDA/ Simplified Disease Activity Index 
Table 3 Treatment-related adverse events reported in at least $1 \%$ of total patients

\begin{tabular}{|c|c|c|c|}
\hline & CT-P13 $(n=302)$ & $\mathrm{RP}(n=300)$ & Total CT-P13 + RP $(n=602)$ \\
\hline Infusion-related reaction & $30(9.9)$ & $43(14.3)$ & $73(12.1)$ \\
\hline Latent TB & $22(7.3)$ & $20(6.7)$ & $42(7.0)$ \\
\hline Upper respiratory tract infection & $23(7.6)$ & $14(4.7)$ & $37(6.1)$ \\
\hline Abnormal liver function test & $22(7.3)$ & $14(4.7)$ & $36(6.0)$ \\
\hline Urinary tract infection & $9(3.0)$ & $11(3.7)$ & $20(3.3)$ \\
\hline Lower respiratory tract infection & $10(3.3)$ & $9(3.0)$ & $19(3.2)$ \\
\hline Flare in RA activity & $7(2.3)$ & $5(1.7)$ & $12(2.0)$ \\
\hline Herpes virus infection & $3(1.0)$ & $7(2.3)$ & $10(1.7)$ \\
\hline Anemia & $4(1.3)$ & $5(1.7)$ & $9(1.5)$ \\
\hline Headache & $4(1.3)$ & $5(1.7)$ & $9(1.5)$ \\
\hline Rash & $2(0.7)$ & $4(1.3)$ & $6(1.0)$ \\
\hline Pyrexia & $1(0.3)$ & $5(1.7)$ & $6(1.0)$ \\
\hline
\end{tabular}

$R A$ rheumatoid arthritis, $R P$ reference product (i.e. reference infliximab), $T B$ tuberculosis

Data are presented as count (percentage)

proportion of patients who discontinued study treatment due to TEAEs was similar between the two groups: 33 patients $(10.9 \%)$ in the CT-P13 group and 47 patients $(15.7 \%)$ in the RP group; 29 (9.6\%) and 37 (12.3\%) patients, respectively, discontinued due to TEAEs considered to be related to treatment. Treatment-related events that caused discontinuation and occurred in more than one patient were infusionrelated reaction $(n=14[4.6 \%])$, TB $(n=3[1.0 \%])$, anemia $(n=2[0.7 \%])$, and abnormal liver function test $(n=2[0.7 \%])$ in the CT-P13 group and infusionrelated reaction $(n=17[5.7 \%])$ and latent TB $(n=5$ [1.7\%]) in the RP group. One death in the RP group was reported during the study. The cause was unknown and not considered to be related to the study treatment.

\section{Pharmacokinetics and pharmacodynamics}

The PK and PD findings were highly comparable between the CT-P13 and RP groups. In the overall PK patient population, serum drug concentrations were similar throughout the study in the CT-P13 and RP groups (Fig. 5). In terms of PD, mean CRP and ESR levels decreased from baseline at all time points (weeks 14, 30 and 54). Respective mean decreases were similar in the CT-P13 and RP groups at week 54 for both CRP $(0.67 \pm 2.17$ and $0.66 \pm 2.66)$ and ESR $(12.3 \pm 22.13$ and $15.2 \pm 21.89$ ).

\section{Discussion}

The 54-week findings from this randomized, doubleblind, multicenter, multinational, parallel-group, prospective phase III study confirm those previously

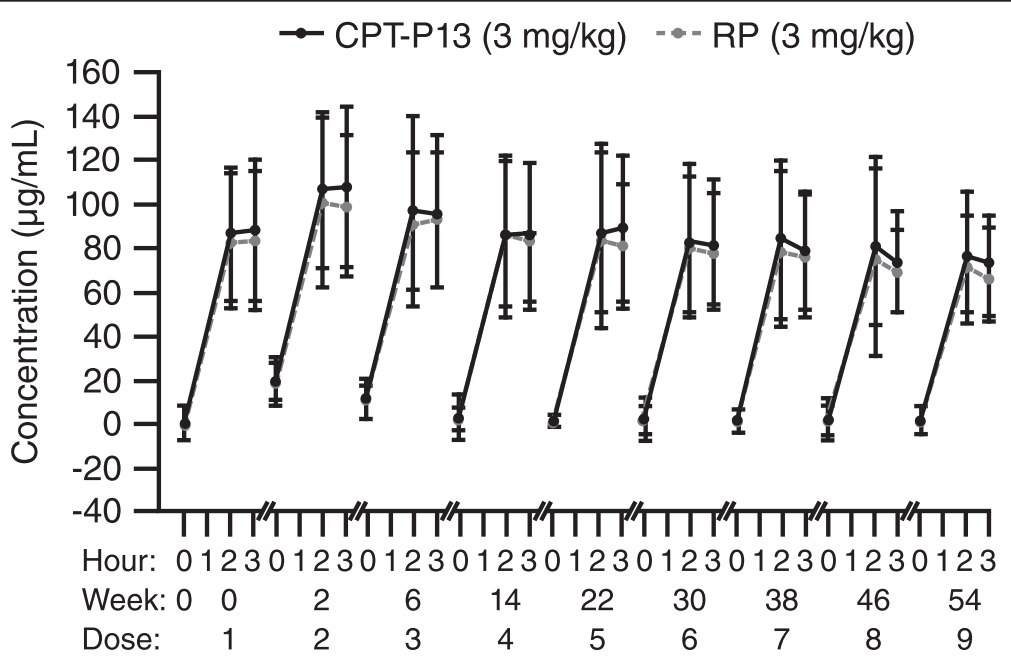

Fig. 5 Serum concentrations of infliximab (mean \pm SD) versus time in the CT-P13 and RP treatment groups in the pharmacokinetic population. RP reference product (i.e., reference infliximab), SD standard deviation 
reported at week 30 [14]. The results show that CTP13 $(3 \mathrm{mg} / \mathrm{kg})$ and RP $(3 \mathrm{mg} / \mathrm{kg})$ are comparable in terms of efficacy, immunogenicity, safety and PK-PD in patients with active RA not responding adequately to MTX.

As previously reported for this study, the ACR20 response at week 30 (primary study endpoint) was equivalent for CT-P13 and RP, as the $95 \%$ CIs for treatment difference were within the predefined margins for equivalence [14]. Similarly, at week 54, the efficacy of CT-P13 and RP was highly comparable across a broad range of measures of disease activity, including ACR responses and DAS28-ESR, DAS28CRP, SDAI and CDAI, as well as PROs, including VAS scores for the patient assessment of pain and the patient global assessment of disease activity, HAQ scores and SF-36 scores.

Regarding the assessment of JDP, the handling of missing data and use of appropriate statistical techniques are important when analyzing radiographic results of a clinical trial. If several different methods of analysis give comparable results, the credibility of the data is increased [15]. CT-P13 showed comparable results when analyzed using either of two different missing data imputations or when missing data were excluded. The proportion of patients with no radiographic progression in total Sharp score was also similar in the two groups when using linear interpolation or extrapolation.

While there are limitations associated with comparing data across studies, the ACR responses we observed at week 54 were generally in the range of those reported in two previous randomized studies with RP in similar patient populations $[16,17]$. For example, between weeks 52 and 54, ACR20 responses with RP ranged from $42 \%$ to $56 \%$ in these historical published studies (ITT analyses) $[16,17]$. The ACR20 associated with CT-P13 in the present study was $57 \%$ at week 54 (ITT analysis). In line with findings at week 0 [14], PK-PD parameters remained comparable between the CT-P13 and RP treatment groups at week 54. Serum drug concentrations and decreases in CRP and ESR levels were similar with both CT-P13 and RP throughout the study. These data are supported by the findings from the PLANETAS study [18], which also showed that CT-P13 and RP have similar effects on efficacy and PK-PD. The safety profile of CT-P13 observed in the present analysis was also similar to that of RP, and both agents were shown to be well tolerated through to week 54 . The safety results were generally aligned with the findings from previous randomized trials of RP up to week 54 in patients with RA $[16,17,19]$.

Data from the present study and a similar trial in patients with ankylosing spondylitis (PLANETAS) $[18,20]$ have shown that CT-P13 and RP possess comparable clinical efficacy, PK-PD and safety when used for over 1 year. Assuming that the biosimilar is priced less than the reference biologic-and in the European Union, biosimilars are generally approximately $30 \%$ less expensive than reference products [21] - CT-P13 may prove to be a costeffective alternative to infliximab RP. In this regard, a budget impact analysis recently assessed the potential effects of introducing CT-P13 for the treatment of RA in six central and eastern European countries. This analysis estimated savings of $€ 20.8$ million over 3 years if $80 \%$ of patients taking RP switched to CT-P13, on the assumption that the price of CT-P13 is $75 \%$ that of the RP [22]. In other countries, such as Norway and Denmark, biosimilar infliximab is recommended by tender systems and, indeed, it has rapidly increased market share in Norway due to the large difference in price between the reference product and the biosimilar [23]. The National Institute for Health and Care Excellence (NICE) in the United Kingdom changed its position on the use of infliximab for the treatment of ankylosing spondylitis by recommending the least expensive drug [24]. They also recommend using the least expensive infliximab for RA treatment [25]. The increasing use of biosimilars in the treatment of various inflammatory diseases may enhance reductions or discounts of the originator biologic's price $[21,26]$. This trend may finally increase accessibility to biologics and reduce total cost further.

The efficacy and safety of CT-P13 up to 102 weeks is being assessed in an extension of the present study, which is also evaluating switching treatment from RP to CT-P13 in patients with RA. The findings from the extension may support the longer-term efficacy and safety of CT-P13.

The main limitation of the present analysis is that the study sample size was calculated to analyze the primary endpoint at 30 weeks. Therefore, the prospective longer-term findings presented here at 54 weeks were not a key consideration when calculating the sample size.

\section{Conclusions}

This randomized, multinational study in patients with active RA inadequately responding to MTX demonstrated that CT-P13 had comparable efficacy, immunogenicity and PK-PD to RP up to week 54 . Additionally, CT-P13 was well tolerated, with a safety profile comparable to that of RP up to week 54 .

\section{Additional files}

Additional file 1: (A) American College of Rheumatology (ACR) response rates over time in the intent-to-treat population, with NRI approach. (B). American College of Rheumatology (ACR) response rates over time in the intent-to-treat population, with LOCF approach. To estimate the difference in proportions between the two treatment groups, we used the exact 
binomial test. ACR20, ACR50 and ACR70 denote the ACR $20 \%$, $50 \%$ and $70 \%$ improvement criteria, respectively. ACR, American College of Rheumatology; $\mathrm{Cl}$, confidence interval; LOCF, last observation carried forward; NRI, nonresponder imputation; RP, reference product (i.e. reference infliximab). (TIF $1024 \mathrm{~kb}$ )

Additional file 2: Changes in efficacy parameters over time with CT-P13 and RP in the intent-to-treat population. (A) Disease activity based on DAS28-ESR; (B) Disease activity based on DAS28-CRP; (C) Disease activity based on SDAl; (D) Disease activity based on CDAl; (E) EULAR response criteria based on DAS28-ESR score; (F) EULAR response criteria based on DAS28-CRP score. *Proportional odds model with EULAR as response, treatment as a fixed effect, and region and CRP category as covariates. An odds ratio $>1$ implied that a patient who received CT-P13 had a higher likelihood of EULAR response than a patient who received RP. The proportional odds assumption implied that the relationship between each pair of outcome response was the same. CDAl, Clinical Disease Activity Index; Cl, confidence interval; CRP, C-reactive protein; DAS28, Disease Activity Score in 28 joints; ESR, erythrocyte sedimentation rate; EULAR, European League Against Rheumatism; RP, reference product (i.e., reference infliximab); SD, standard deviation; SDAl, Simplified Disease Activity Index. (TIF $1420 \mathrm{~kb}$ )

Additional file 3: Improvement in patient-reported outcomes with CT-P13 and RP in the intent-to-treat population. (DOC $52 \mathrm{~kb}$ )

Additional file 4: Overview of treatment-related serious adverse events occurring by severity ( $\mathrm{n}[\%])$. (DOC $49 \mathrm{~kb}$ )

\section{Abbreviations}

ACR: American College of Rheumatology; ADA: antidrug antibody; AE: adverse event; ANCOVA: analysis of covariance; BMI: body mass index; CCP: cyclic citrullinated peptide; CDAl: Clinical Disease Activity Index; Cl: confidence interval; CRP: C-reactive protein; DAS28: Disease Activity Score in 28 joints; ESR: erythrocyte sedimentation rate; EULAR: European League Against Rheumatism; HAQ: Health Assessment Questionnaire; Ig: immunoglobulin; IGRA: interferon $\gamma$-release assay; ITT: intent-to-treat; JDP: joint damage progression; LOCF: last observation carried forward; MTX: methotrexate; NAbs: neutralizing activity of antidrug antibodies; NICE: National Institute for Health and Care Excellence; NRI: nonresponder imputation; PD: pharmacodynamics; PK: pharmacokinetics;

PLANETRA: Programme evaLuating the Autoimmune disease iNvEstigational drug CT-p13 in RA patients; PP: per-protocol; PRO: patient-reported outcome; RA: rheumatoid arthritis; RF: rheumatoid factor; RP: reference product; SD: standard deviation; SDAl: Simplified Disease Activity Index; SF-36: Medical Outcomes Study Short Form Health Survey; SJC: swollen joint count; TB: tuberculosis; TEAE: treatment-emergent adverse event; TJC: tender joint count; TNF: tumor necrosis factor; VAS: visual analogue scale.

\section{Competing interests}

$D H Y$ and WP are consultants for CELLTRION. AB reports receiving personal fees from AbbVie and grants from Samsung Bioepis and AbbVie, outside the submitted work. SSH and SYL are employees of CELLTRION. The other authors declare that they have no competing interests.

\section{Authors' contributions}

DHY, WP, SSH, and SYL were involved in the conception and design of the study, and/or analysis and interpretation of data; drafting of the manuscript and revising it critically for important intellectual content. AR, JB, RY, ETA, AB, CAM, SN, VK, and IGS were involved in the acquisition of data; drafting of the manuscript and revising it critically for important intellectual content. All authors read and approved the final manuscript.

\section{Acknowledgements}

The authors thank the patients and study personnel who made this trial possible and the PLANETRA study investigators—Austria: Zamani O; Bosnia: Mulic Bacic S, Prodanovic N; Bulgaria: Bichovska D, Oparanov B, Rashkov R, Toncheva A; Chile: Aguirre V, Arriagada Herrera M, Barria Negron L, Jimenez R, Miranda P; Colombia: Abello Banfi M, Chalem M, Diaz Cortez M, Otero Escalante WJ, Ruiz Santacruz O; Italy: Bianchi G, Cutolo M, Salvarani C; Jordan: Alawneh K; Latvia: Andersone D, Saleniece S, Saulite-Kandevica D; Lithuania: Bukauskiene L, Kausiene R, Smilgiene V, Stropuviene S; Mexico: Araiza R, Cardona Cabrera R, Cons Molina F, Diaz Jimenez A, Gutierrez-Ureña S,
Morales-Torres J, Pacheco-Tena C, Xibille D; Peru: Calvo A, Castaneda Jimenez M, Chalouhi El-Khouri E, Chavez Corrales J, Morales Olazabal L, Vidal Neira Li Philippines: Amante EJ, Baes R, Eullaran R, Lanzon A, Lucero A Jr, Ramiterre E, Salido E, Tan P, Tee M; Poland: Brzosko M, Daniluk S, Hrycaj P, Jaworski J, Jeka S, Klimiuk P, Krogulek M, Ruzga Z, Piotrowski M, Wiland P; Portugal: Vaz Patto J; Romania: Bojinca VC, Chicea LM, Cristei D, lanuli-Arvunescu MA, Pavel M, Rednic S, losif I; Slovakia: Jancovic R, Krpciar M, Zlnay D; Spain: Blanco Garcia F, Fernández-Nebró A, Gómez Centeno A, Martín-Mola E, Ucar Angulo E; United Kingdom: Adebajo A, Byrne P; Ukraine: Amosova K, Dzyak G, Gnylorybov A, Gyrina O, Hospodarskyy I, Kovalenko V, Lysenko G, Shevchuk S, Polyvoda S, Smiyan S, Yagensky A; United States: Ahn C.

The following ethical bodies approved the study in the centers involved: Austria: Ethikkommission der Medizinischen Universität Graz; Bosnia: LEC at Clinical Center University of Sarajevo; LEC University Clinical Center Tuzla; LEC Clinical Center Banja Luka; Bulgaria: Ethics Committee for Multi-centre Trials; Chile: Comite de Evaluacion Etico Cientifico del Servicio de Salud Vina del Mar Quillota Hospital Dr. Gusta; Comite de Etica de la Investigacion Servicio de Salud Valdivia; Comite de Evaluacion de Etica Cientifico del Servicio de Salud Metropolitano Oriente; Colombia: Comité de Ética en Investigación Servimed; Comité de Etica Fundación Instituto de Reumatología Fernando Chalem; Comité de Ética Universidad del Norte; Comite de Etica de la Investigacion Riesgo de Fractura SA; Italy: Comitato Etico Azienda Ospedaliera Universitaria San Martino; Comitato Etico della ASL 3 Genovese di Genova; Comitato Etico Provinciale di Reggio Emilia; Jordan: IRB of King Abdullah University Hospital; IRB of Jordan Hospital; Latvia: The Ethics Committee for Clinical Trials on Medicinal Products; Lithuania: Lithuanian Bioethics Committee; Mexico: Comite de Investigacion y Etica del Hospital Central "Dr. Ignacio Morones Prieto"; Comite de Etica del Hospital Inovamed; Comite Bioetico para la Investigacion Clinica S.C. Institutional Review Board; Comité de Ética e Investigación Christus. Muguerza del Parque SA de CV; Comite de Investigacion, Educacion y Etica del Hospital Real San Jose; Comité de Enseñanza, Investigación y Ética del Hospital Civil de Guadalajara Fray Antonio Alcalde; Comité de Etica e Investigación del Hospital Aranda de la Parra; Peru: Comite Institucional de Bioetica (CIB); Comite Institucional de Etica en Investigacion Hospital Maria Auxiliadora; Philippines: Mary Mediatrix Medical Center; De La Salle - Health Sciences Campus Institutional and Ethics Review Board; Research and Biotechnology Division Institutional Ethics Reveiw Board; Brokenshire Memorial Hospital Ethics Committee; Asian Hospital and Medical Center, Institution Review Board; Medical Center Manila, Institution Review Board; Ethics Review Committee Chong Hua Hospital; Institutional Research Ethics Committee; Research Implementation and Development Office; FEU-NRMF Medical Center, Bioethics Review Committee; Poland: Komisja Bioetyczna przy Okregowej Radzie Lekarskiej Wielkopolskiej Izby Lekarskiej w Poznaniu; Portugal: Comissão de Ética para a Investigação Clinica; Romania: National Ethics Committee for Clinical Trial on Medicine; Slovak Republic: Eticka komisia Narodneho ustavu reumatickych chorob; Spain: CEIC-E (Comité Etico de Investigación Clínica de Euskadi); CEIC de Galicia (SERGAS); CEIC Hospital Universitario de Canarias; CEIC de Andalucía; CEIC Hospital La Paz; CEIC de la Corporacion Sanitaria del Parc Tauli; Ukraine: Central Commission on Ethics Questions of the MoH of Ukraine; United Kingdom: NRES Committee East Midlands-Northampton. This work was funded by CELLTRION Inc. The funding body contributed to the design of the study and the collection, analysis, and interpretation of data; and reviewed drafts and the final version of the manuscript. The final decision to submit the manuscript was taken by the authors. Editorial support (writing assistance, assembling tables and figures, collating author comments, grammatical editing and referencing) was provided by Ryan Woodrow (Aspire Scientific Limited, Bollington, UK) and was funded by CELLTRION Healthcare Co., Ltd (Incheon, Republic of Korea).

\section{Author details}

${ }^{1}$ Hanyang University Hospital, Seoul, Republic of Korea. ${ }^{2}$ NZOZ Osteo-Medic, Bialystok, Poland. ${ }^{3}$ Wojewodzki Szpital Zespolony, Elblag, Poland. ${ }^{4}$ Ivano-Frankivsk Regional Clinical Hospital, Ivano-Frankivsk, Ukraine. ${ }^{5}$ Hospital Militar Central, Bogota, Colombia. 'Lithuanian University of Health Sciences, Kaunas, Lithuania. ${ }^{7}$ Hospital Central Dr. Ignacio Morones Prieto, San Luis Potosi, Mexico. ${ }^{8}$ St. Luke's Medical Center, Quezon City, Philippines. ${ }^{9}$ University Hospital St. Marina, Varna, Bulgaria. ${ }^{10}$ Prosalud y Cia Ltda, Santiago, Chile. ${ }^{11}$ CELLTRION, Incheon, Republic of Korea. ${ }^{12}$ Inha University Hospital, Incheon, Republic of Korea. 
Received: 5 October 2015 Accepted: 23 March 2016

\section{Published online: 02 April 2016}

\section{References}

1. Maini R, St Clair EW, Breedveld F, et al. Infliximab (chimeric anti-tumour necrosis factor a monoclonal antibody) versus placebo in rheumatoid arthritis patients receiving concomitant methotrexate: a randomised phase III trial. Lancet. 1999;354:1932-9.

2. Maini RN, Breedveld FC, Kalden JR, et al. Therapeutic efficacy of multiple intravenous infusions of anti-tumor necrosis factor a monoclonal antibody combined with low-dose weekly methotrexate in rheumatoid arthritis. Arthritis Rheum. 1998;41:1552-63.

3. Smolen JS, Aletaha D, Bijlsma JW, et al. Treating rheumatoid arthritis to target: recommendations of an international task force. Ann Rheum Dis. 2010;69:631-7.

4. Putrik P, Ramiro S, Kvien TK, et al. Inequities in access to biologic and synthetic DMARDs across 46 European countries. Ann Rheum Dis. 2014;73:198-206.

5. Nast A, Mrowietz U, Kragballe K, et al. Barriers to the prescription of systemic therapies for moderate-to-severe psoriasis - a multinational cross-sectional study. Arch Dermatol Res. 2013;305:899-907.

6. World Health Organization, Expert Committee on Biological Standardization. Guidelines on evaluation of similar biotherapeutic products (SBPs). Geneva, Switzerland: 19-23 Oct 2009. http://www.who.int/biologicals/areas/ biological_therapeutics/BIOTHERAPEUTICS_FOR_WEB_22APRIL2010.pdf. Accessed 25 Mar 2016

7. Dorner T, Strand V, Castaneda-Hernandez G, et al. The role of biosimilars in the treatment of rheumatic diseases. Ann Rheum Dis. 2013;72:322-8.

8. Abraham I, Han L, Sun D, et al. Cost savings from anemia management with biosimilar epoetin alfa and increased access to targeted antineoplastic treatment: a simulation for the EU G5 countries. Future Oncol. 2014;10:1599-609.

9. Horbrand F, Rottenkolber D, Fischaleck J, et al. Erythropoietin-induced treatment costs in patients suffering from renal anemia - a comparison between biosimilar and originator drugs. Gesundheitswesen. 2014;76:e79-84.

10. Haustein R, de Millas $C$, Höer A, et al. Saving money in the European healthcare systems with biosimilars. GaBI J. 2012;1:120-6.

11. Lapadula G, Ferraccioli GF. Biosimilars in rheumatology: pharmacological and pharmacoeconomic issues. Clin Exp Rheumatol. 2012:30(4 Suppl 73):S102-6.

12. European Medicines Agency, Committee for Medicinal Products for Human Use (CHMP). Assessment report: Remsima (infliximab). 27 Jun 2013. http:// www.ema.europa.eu/docs/en_GB/document_library/EPAR_-_Public_ assessment_report/human/002576/WC500151486.pdf. Accessed 25 Mar 2016.

13. Jung SK, Lee KH, Jeon JW, et al. Physicochemical characterization of Remsima ${ }^{\oplus}$. MAbs. 2014;6:1163-77.

14. Yoo DH, Hrycaj P, Miranda P, et al. A randomised, double-blind, parallelgroup study to demonstrate equivalence in efficacy and safety of CT-P13 compared with innovator infliximab when coadministered with methotrexate in patients with active rheumatoid arthritis: the PLANETRA study. Ann Rheum Dis. 2013;72:1613-20.

15. van der Heijde D, Landewé $R$, Klareskog $L$, et al. Presentation and analysis of data on radiographic outcome in clinical trials: experience from the TEMPO study. Arthritis Rheum. 2005;52:49-60.

16. Schiff M, Keiserman M, Codding C, et al. Efficacy and safety of abatacept or infliximab vs placebo in ATTEST: a phase III, multi-centre, randomised, doubleblind, placebo-controlled study in patients with rheumatoid arthritis and an inadequate response to methotrexate. Ann Rheum Dis. 2008;67:1096-103.

17. Lipsky PE, van der Heijde DM, St Clair EW, et al. Infliximab and methotrexate in the treatment of rheumatoid arthritis. N Engl J Med. 2000;343:1594-602.

18. Park W, Hrycaj P, Jeka S, et al. A randomised, double-blind, multicentre, parallel-group, prospective study comparing the pharmacokinetics, safety, and efficacy of CT-P13 and innovator infliximab in patients with ankylosing spondylitis: the PLANETAS study. Ann Rheum Dis. 2013;72:1605-12.

19. St Clair EW, van der Heijde DM, Smolen JS, et al. Combination of infliximab and methotrexate therapy for early rheumatoid arthritis: a randomized, controlled trial. Arthritis Rheum. 2004;50:3432-43.

20. Park W, Yoo DH, Jaworski J, et al. Comparable long-term efficacy, as assessed by patient-reported outcomes, safety and pharmacokinetics, of CTP13 and reference infliximab in patients with ankylosing spondylitis: 54week results from the randomized, parallel-group PLANETAS study. Arthritis Res Ther. 2016;18:25.

21. Blackstone EA, Joseph PF. The economics of biosimilars. Am Health Drug Benefits. 2013;6:469-78.
22. Brodszky V, Baji P, Balogh O, et al. Budget impact analysis of biosimilar infliximab (CT-P13) for the treatment of rheumatoid arthritis in six Central and Eastern European countries. Eur J Health Econ. 2014;15 Suppl 1:S65-71.

23. Mack A. Norway, biosimilars in different funding systems. What works? GaBI J. 2015:4(2):90-2.

24. National Institute for Health and Care Excellence (NICE). TNF-a inhibitors for ankylosing spondylitis and non-radiographic axial spondylarthritis. NICE technology appraisal guidance [TA383]. London: NICE; Feb 2016. https:// www.nice.org.uk/guidance/ta383. Accessed 25 Mar 2016.

25. National Institute for Health and Care Excellence (NICE). Adalimumab, etanercept, infliximab, certolizumab pegol, golimumab, tocilizumab and abatacept for rheumatoid arthritis not previously treated with DMARDs or after conventional DMARDs only have failed. NICE technology appraisal guidance [TA375]. London: NICE; January 2016. http://www.nice.org.uk/ guidance/ta375. Accessed 25 Mar 2016.

26. Mestre-Ferrandiz J, Towse A, Berdud M. Biosimilars: how can payers get longterm savings? Pharmacoeconomics. 2016. In press.

\section{Submit your next manuscript to BioMed Central and we will help you at every step:}

- We accept pre-submission inquiries

- Our selector tool helps you to find the most relevant journal

- We provide round the clock customer support

- Convenient online submission

- Thorough peer review

- Inclusion in PubMed and all major indexing services

- Maximum visibility for your research

Submit your manuscript at www.biomedcentral.com/submit
C Biomed Central 